\title{
Metabolic pathways of Pseudomonas aeruginosa involved in competition with respiratory bacterial pathogens
}

\author{
Marie Beaume ${ }^{1,2 \dagger}$, Thilo Köhler ${ }^{1,2 \dagger}$, Thierry Fontana1,2, Mikael Tognon ${ }^{1,2}$, Adriana Renzoni ${ }^{1}$ \\ and Christian van Delden ${ }^{1,2 *}$ \\ 'Service of Infectious Diseases, Department of Medical Specialities, University Hospitals Geneva, Geneva, Switzerland, \\ ${ }^{2}$ Department of Microbiology and Molecular Medicine, University of Geneva, Geneva, Switzerland
}

\section{OPEN ACCESS}

Edited by:

Evangelos Giamarellos-Bourboulis, University of Athens, Medical School,

Greece

Reviewed by:

$\mathrm{LiXu}$

Cornell University, USA Eirini Christaki,

AHEPA University Hospital

of Thessaloniki, Greece

*Correspondence:

Christian van Delden,

Service of Infectious Diseases, Department of Medical Specialities, University Hospitals Geneva, 4 Rue

Gabrielle-Perret-Gentil, CH-1211

Genève, Switzerland

christian.vandelden@hcuge.ch

${ }^{\dagger}$ These authors have contributed equally to this work.

Specialty section: This article was submitted to Infectious Diseases,

a section of the journa

Frontiers in Microbiology

Received: 17 February 2015 Accepted: 31 March 2015

Published: 23 April 2015

Citation:

Beaume M, Köhler T, Fontana T,

Tognon M, Renzoni A and van Delden C (2015) Metabolic pathways of Pseudomonas aeruginosa involved in competition with respiratory bacterial pathogens.

Front. Microbiol. 6:321. doi: 10.3389/fmicb.2015.00321
Background: Chronic airway infection by Pseudomonas aeruginosa considerably contributes to lung tissue destruction and impairment of pulmonary function in cystic-fibrosis (CF) patients. Complex interplays between $P$. aeruginosa and other cocolonizing pathogens including Staphylococcus aureus, Burkholderia sp., and Klebsiella pneumoniae may be crucial for pathogenesis and disease progression.

Methods: We generated a library of PA14 transposon insertion mutants to identify $P$. aeruginosa genes required for exploitative and direct competitions with $S$. aureus, Burkholderia cenocepacia, and K. pneumoniae.

Results: Whereas wild-type PA14 inhibited S. aureus growth, two transposon insertions located in pqsC and carB, resulted in reduced growth inhibition. PqsC is involved in the synthesis of 4-hydroxy-2-alkylquinolines (HAQs), a family of molecules having antibacterial properties, while carB is a key gene in pyrimidine biosynthesis. The carB mutant was also unable to grow in the presence of $B$. cepacia and $K$. pneumoniae but not Escherichia coli and S. epidermidis. We further identified a transposon insertion in purF, encoding a key enzyme of purine metabolism. This mutant displayed a severe growth deficiency in the presence of Gram-negative but not of Gram-positive bacteria. We identified a beneficial interaction in a bio $A$ transposon mutant, unable to grow on rich medium. This growth defect could be restored either by addition of biotin or by co-culturing the mutant in the presence of $K$. pneumoniae or $E$. coli.

Conclusion: Complex interactions take place between the various bacterial species colonizing CF-lungs. This work identified both detrimental and beneficial interactions occurring between $P$. aeruginosa and three other respiratory pathogens involving several major metabolic pathways. Manipulating these pathways could be used to interfere with bacterial interactions and influence the colonization by respiratory pathogens.

Keywords: direct competition, exploitative competition, respiratory pathogens, Pseudomonas aeruginosa, beneficial interactions, Staphylococcus aureus 


\section{Introduction}

The composition of the microbial respiratory flora of cystic fibrosis (CF) patients changes with age; Haemophilus influenzae and Staphylococcus aureus being present mainly in young children, while Pseudomonas aeruginosa, S. aureus, and Burkholderia sp. predominate in older patients (Goss and Burns, 2007; Cox et al., 2010; Lipuma, 2010). At the age of $20,60-70 \%$ of CF-patients present intermittent colonization by $P$. aeruginosa (Folkesson et al., 2012) which progressively evolves toward a chronic colonization, that entails progressive lung tissue damage and impairment of pulmonary function. The disappearance of the early colonizing species may be explained by antibiotic treatments or by competition between co-colonizing microorganisms. Many ecological factors, including host immune responses as well as the presence of co-colonizing species interacting with $P$. aeruginosa by competition and/or cooperation, determine the dynamics of lung colonization. Bacterial interference occurs either via direct competition characterized by an active mechanism including the type VI secretion systems (Pukatzki et al., 2006; Basler et al., 2013) and production of competitor molecules (siderophores, secondary metabolites, toxins), or via exploitative competition where one organism consumes the resources of another (Cornforth and Foster, 2013; Boon et al., 2014). For example, $P$. aeruginosa can lyse $S$. aureus to obtain iron under iron-starvation conditions using LasA protease (Mashburn et al., 2005), and 4-hydroxy-2-heptylquinoline $\mathrm{N}$ oxide (HQNO) allows $P$. aeruginosa to inhibit the cytochrome oxidase of S. aureus (Lightbown and Jackson, 1954; Machan et al., 1992; Toder et al., 1994). Furthermore, recent results demonstrated that compounds such as phenazines inhibit methicillinresistant S. aureus (MRSA; Cardozo et al., 2013). Besides active competition, regulatory effects induced for instance by the resident flora can induce the expression of important virulence and metabolic genes in $P$. aeruginosa (Duan et al., 2003). In addition, positive interactions can also occur between microorganisms during polymicrobial infections. For example, $P$. aeruginosa can induce the formation of small colony variants in $S$. aureus, leading to an increased resistance of the latter to aminoglycoside antibiotics (Hoffman et al., 2006). This indicates that interspecies competition and cooperation play an important role in shaping composition and structure of polymicrobial bacterial populations, thereby potentially influencing disease progression. Increasing our understanding of these interactions is crucial (Bragonzi et al., 2012) and might lead to the identification of new targets aiming at manipulating interactions inside polymicrobial communities to the disadvantage of pathogens such as P. aeruginosa.

In this perspective we developed a broad genetic screen to identify $P$. aeruginosa genes required for direct and exploitative competition. We searched for $P$. aeruginosa mutants affected in growth in the presence of $S$. aureus, Klebsiella pneumoniae, or B. cepacia. In addition, we examined $P$. aeruginosa mutants altered in their capacity to inhibit growth of $S$. aureus.

\section{Materials and Methods}

\section{Bacterial Strains, Growth Conditions and Media}

All $P$. aeruginosa mutants used in this study are derived from the clinical strain PA14 (Rahme et al., 1995; Table 1). All genetic manipulations were performed in Escherichia coli strain DH10B. E. coli strain SM10- $\lambda$ pir was used for conjugating plasmids into $P$. aeruginosa. Three bacterial pathogens were used for the initial screening: the S. aureus clinical strain COL (Dyke et al., 1966), a clinical Burkholderia cenocepacia isolate (University Hospitals of Geneva) and a non-capsulated K. pneumoniae strain (laboratory collection). The S. epidermidis and the E. coli strains were isolated from tracheal aspirates of two CF patients followed at the University Hospitals of Geneva (Geneva, Switzerland).

When required, plates were supplemented with $1 \mathrm{mM}$ uracil, $1 \mathrm{mM}$ arginine, or $2 \mathrm{mg} / \mathrm{L}$ biotin (final concentrations). For growth under hypoxic conditions, LB plates were supplemented with $5 \mathrm{mM} \mathrm{KNO}_{3}$ and incubated in a jar using the GasPak Plus kit (BBL) (final $\mathrm{O}_{2}$ concentration $<0.2 \%$ ).

\section{Generation of the P. aeruginosa PA14 Transposon (Tn) Mutant Library}

The E. coli SM10- $\lambda$ pir donor strain containing pBT20 (Kulasekara et al., 2005) and the recipient $P$. aeruginosa PA14 were grown overnight at $37^{\circ} \mathrm{C}$ with shaking $(250 \mathrm{rpm})$ in LB-broth. $200 \mu \mathrm{L}$ of the donor and $100 \mu \mathrm{L}$ of the recipient culture were mixed and centrifuged at $6,000 \mathrm{rpm}$ for $2 \mathrm{~min}$. The pellet was resuspended in $20 \mu \mathrm{L}$ of LB and deposited on an LB agar plate. After $5 \mathrm{~h}$ of incubation at $37^{\circ} \mathrm{C}$, cells were resuspended in $1 \mathrm{~mL} 0.9 \% \mathrm{NaCl}$ and $100 \mu \mathrm{L}$ of the suspension were plated on LB agar medium containing gentamicin $(50 \mathrm{mg} / \mathrm{L})$ and chloramphenicol $(10 \mathrm{mg} / \mathrm{L})$. To test for random distribution of Tn-insertions, 200 transconjugants were picked and streaked on minimal M9-salts medium supplemented with $0.2 \%$ glucose and $1 \mathrm{mM} \mathrm{MgSO}_{4}$ and on an LB-agar plate. Approximately $1 \%$ of clones were auxotrophic, which is agreement with a random transposition event.

\section{Growth Competition Screening}

Overnight cultures of bacterial competitors were adjusted to $\mathrm{OD}_{600}=0.5$. A $500 \mu \mathrm{L}$ aliquot of fivefold (S. aureus and S. epidermidis) and 100-fold (B. cepacia, K. pneumoniae, and E. coli) dilutions were plated on agar plates. Bacterial lawns were incubated $2 \mathrm{~h}$ at $37^{\circ} \mathrm{C}$. Overnight cultures of $P$. aeruginosa transposon mutants were adjusted to $\mathrm{OD}_{600}=2$ and $1 \mu \mathrm{L}$ of each culture was spotted on the competitor lawns using a 48-pin inoculator. As control, cells were spotted on a plate without competitors. Plates were incubated $18 \mathrm{~h}$ at $37^{\circ} \mathrm{C}$. Mutants were initially screened for: (i) an alteration of the inhibition zone on the S. aureus lawn on Mueller Hinton agar, and (ii) an alteration of $P$. aeruginosa growth on lawns of B. cepacia and $K$. pneumoniae on LB-agar.

\section{Identification of the Transposon Insertion Site}

The transposon insertion site was identified by a two-step semirandom PCR (Friedman and Kolter, 2004; Kulasekara et al., 
TABLE 1 | Plasmids and strains.

\begin{tabular}{|c|c|c|}
\hline Plasmids or strains & Description & Reference \\
\hline \multicolumn{3}{|l|}{ Plasmids } \\
\hline plApX2 & Broad-host-range cloning vector, pUCP20 derivative & $\begin{array}{l}\text { I. Attree (Grenoble, France; } \\
\text { West et al., 1994) }\end{array}$ \\
\hline pME3087 & Mobilizable suicide vector, ColE1 & Voisard et al. (2007) \\
\hline pMMB207 & Expression plasmid with inducible tac/lacUV5 promoter & Morales et al. (1991) \\
\hline pPqsCDE & pqsCDE PCR fragment cloned into pIApX2 by using Xbal (Roche) and HindIII (Roche) & This study \\
\hline pCarB & carB PCR fragment cloned into plApX2 by using HindllI (Roche) and BamHI (Roche) & This study \\
\hline pBioA & bioA PCR fragment cloned into pMMB207 by using Kpnl (NEB) and BamHI (Roche) & This study \\
\hline pPurF & purF PCR fragment cloned into pMMB207 by using Kpnl (NEB) and BamHI (Roche) & This study \\
\hline \multicolumn{3}{|l|}{ Strains } \\
\hline PA14 & Clinical isolate UCBPP-PA14 & Rahme et al. (1995) \\
\hline PA14 carB::Tn & Transposon inserted into the carB gene & This study \\
\hline PA14 pqsC::Tn & Transposon inserted into the pqsC gene & This study \\
\hline PA14 purF::Tn & Transposon inserted into the purF gene & This study \\
\hline PA14 bioA::Tn & Transposon inserted into the bioA gene & This study \\
\hline PA14 carB::Tn pCarB & carB-disrupted Pseudomonas aeruginosa containing the pCarB complementation plasmid & This study \\
\hline PA14 pqsC::Tn pPqsCDE & pqsC-disrupted $P$. aeruginosa containing the pPqsCDE complementation plasmid & This study \\
\hline PA14 purF::Tn pPurF & purF-disrupted $P$. aeruginosa containing the pPurF complementation plasmid & This study \\
\hline PA14 bioA::Tn pBioA & bioA-disrupted $P$. aeruginosa containing the pBioA complementation plasmid & This study \\
\hline PA14 carB::Tn plApX2 & carB-disrupted $P$. aeruginosa containing the plApX2 plasmid & This study \\
\hline PA14 pqsC::Tn plApX2 & pqsC-disrupted $P$. aeruginosa containing the plApX2 plasmid & This study \\
\hline PA14 purF::Tn pMMB207 & purF-disrupted $P$. aeruginosa containing the pMMB207 plasmid & This study \\
\hline PA14 bioA::Tn pMMB207 & bioA-disrupted $P$. aeruginosa containing the pMMB207 plasmid & This study \\
\hline PA14 $\Delta$ lasA & LasA-deleted $P$. aeruginosa PA14 strain & This study \\
\hline $\mathrm{PAO} 1 \Delta$ pqsA pqsA::lux & $\begin{array}{l}\text { PqsA-deleted } P \text {. aeruginosa PAO1 strain with a copy of the pqsA promoter linked to the } \\
\text { luxCDABE genes and inserted into a neutral site in the chromosome }\end{array}$ & Fletcher et al. (2007) \\
\hline PA14 mvfR ${ }^{-}$ & Mutated PA14 strain containing a nonsense point mutation in mvfR & Cao et al. (2001) \\
\hline PA14 pqsA $A^{-}$ & Mutated PA14 strain containing a non-polar deletion of pqsA & Deziel et al. (2004) \\
\hline $\mathrm{PA} 14 \mathrm{pqsH}^{-}$ & Mutated PA14 strain containing a aacC1 cassette inserted into pqsH & Xiao et al. (2006a) \\
\hline PA14 pqs ${ }^{-}$ & Isogenic non-polar pqsL deletion mutant & Lepine et al. (2004) \\
\hline Escherichia coli SM10- $\lambda$ pir & RP4-2-Tc::Mu recA, pir lysogen KmR & Simon et al. (1983) \\
\hline Staphylococcus aureus COL & Clinical strain, MRSA & Dyke et al. (1966) \\
\hline Burkholderia cenocepacia & Clinical strain & $\begin{array}{l}\text { University Hospitals of } \\
\text { Geneva }\end{array}$ \\
\hline Klebsiella pneumoniae & Non-capsulated & Laboratory collection \\
\hline E. coli & Clinical strain from CF-patient & This study \\
\hline S. epidermidis & Clinical strain from CF-patient & This study \\
\hline
\end{tabular}

2005). The first round PCR reaction contained dNTPs $(0.25 \mathrm{mM}$ final), Taq Buffer (1X final, Sigma), DMSO (5\% final concentration), Taq polymerase (2.5 U/reaction, Sigma), and primers MCL195 and ARB1 (Table 2). Four microliters of bacterial lysate served as template. PCR cycling conditions were as follows: $95^{\circ} \mathrm{C}$ for $3 \mathrm{~min}, 36 \mathrm{cycles}$ of $95^{\circ} \mathrm{C}$ for $20 \mathrm{~s}, 30$ to $48^{\circ} \mathrm{C}$ for $40 \mathrm{~s}$ with a $0.5^{\circ} \mathrm{C}$ increase per cycle, $72^{\circ} \mathrm{C}$ for $1 \mathrm{~min}$ and a final extension at $72^{\circ} \mathrm{C}$ for $5 \mathrm{~min}$. In the second round PCR reaction the nested primers ARB2 and MCL210 were used (Table 2). PCR conditions were as follows: $95^{\circ} \mathrm{C}$ for $3 \mathrm{~min}, 30$ cycles of $95^{\circ} \mathrm{C}$ for $30 \mathrm{~s}, 50^{\circ} \mathrm{C}$ for $30 \mathrm{~s}, 72^{\circ} \mathrm{C}$ for $1 \mathrm{~min}$ and a final extension of $72^{\circ} \mathrm{C}$ for $4 \mathrm{~min}$. PCR products were visualized on a $1.6 \%$ agarose gel. The most intense bands were extracted and purified (GeneJet Gel extraction kit, ThermoScientific). The PCR products were then submitted to DNA sequencing (Fasteris SA, Geneva, Switzerland) using the nested primers ARB2 and
MCL210. Each sequence was aligned to the PA14 genome sequence in the Pseudomonas database (Winsor et al., 2011). Confirmation of the transposon insertion was done by PCR using gene and/or transposon specific primers. PCR cycling conditions were: (i) activation: $95^{\circ} \mathrm{C}$ for $2 \mathrm{~min}$, (ii) denaturation: $95^{\circ} \mathrm{C}$ for $20 \mathrm{~s}$, annealing: $57^{\circ} \mathrm{C}$ for $30 \mathrm{~s}$, extension: $72^{\circ} \mathrm{C}$ for $1 \mathrm{~min}$ and $30 \mathrm{~s}$, (iii) final extension: $72^{\circ} \mathrm{C}$ for $4 \mathrm{~min}$. Step 2 was repeated 27 times. PCR products were purified and submitted to DNA sequencing.

\section{Exoproduct Analysis}

Rhamnolipid production was assessed following a previously described protocol (Kohler et al., 2000). Plates were incubated $18 \mathrm{~h}$ at $37^{\circ} \mathrm{C}, 24 \mathrm{~h}$ at room temperature and then $16 \mathrm{~h}$ at $4^{\circ} \mathrm{C}$. The diameter of the rhamnolipid-containing halo formed around the bacterial colony was measured and compared with 
TABLE 2 | Primers used in this study

\begin{tabular}{|c|c|c|c|}
\hline Primers & Amplified gene(s) & Sequences $\left(5^{\prime}-3^{\prime}\right)$ & Final concentration $(\mu \mathrm{M})$ \\
\hline \multicolumn{4}{|c|}{ Semirandom PCR } \\
\hline ARB1 & & GGCCACGCGTCGACTAGTACNNNNNNNNNNGATAT & 0.5 \\
\hline ARB2 & & GGCCACGCGTCGACTAGTAC & 0.4 \\
\hline MCL195 & & GATCCCGCAGTGGCTCTCTATACAAAGTTG & 0.2 \\
\hline MCL210 & & TGGTGCTGACCCCGGATGAAG & 0.4 \\
\hline \multicolumn{4}{|c|}{ Confirmation of the transposon insertion site and complementations* } \\
\hline PurF-Kpn & purF & ACAGGTACCAGTGATITTGGCGGGACAC & 0.6 \\
\hline PurF-BamHI & & ACAGGATCCCCAGGGTGTCGAAGGCC & 0.6 \\
\hline BioA-Kpn & bioA & ACAGGTACCTGAACACCCCCAACATGAGA & 0.6 \\
\hline BioA-R_BamHI & & ACAGGATCCGATTCGAGGGTAGTGGCGAC & 0.6 \\
\hline CarB-F_BamHI & $\operatorname{carB}$ & ACAGGATCCGTTCGTCGATCCCGGCTA & 0.6 \\
\hline CarB-R_Hindlll & & ACAAAGCTICGGCGTITCCTTGAGG & 0.6 \\
\hline pqsC-Xba & pqs CDE & ACACTCTAGATTCGAACTGGCGTCGCAAC & 0.6 \\
\hline pqsC-Hind & & ACACAAGCTTCTTCCAGTCGATAGCCAACC & 0.6 \\
\hline \multicolumn{4}{|l|}{ lasA deletion* } \\
\hline LasAF-Eco & $5^{\prime}$ las A region & CCCGGAATTCAGGATAACGTCGGCATGGAC & 0.6 \\
\hline LasAR-Bam & & CCGCGGATCCTGCTCCAGGTATTCGCTCTTG & 0.6 \\
\hline LasAF-Bam & $3^{\prime}$ las $A$ region & CCGCGGATCCACCAGATCCAGGTGAGCAACG & 0.6 \\
\hline LasAR-Hind & & CCCCAAGCTITCGGAGTCCGGCTACTACGC & 0.6 \\
\hline
\end{tabular}

* Restriction enzyme recognition sites are underlined

that produced by the reference strain PA14. Determinations were done in duplicates.

Elastase activity was determined using the Elastin Congo Red assay with modifications (Pearson et al., 1997). Overnight cultures of $P$. aeruginosa strains were prepared in LB medium supplemented with $1 \mathrm{mM}$ uracil to optimize the growth of the strain PA14 carB::Tn. Cultures were grown for $7 \mathrm{~h}$ at $37^{\circ} \mathrm{C}$ in PB medium (Essar et al., 1990). The $\mathrm{OD}_{600}$ was measured and elastase activity determined in supernatants using the Elastin Congo Red assay measuring absorption at $\mathrm{OD}_{495}$. All determinations were done in triplicate and expressed as the ratio of $\mathrm{OD}_{495} / \mathrm{OD}_{600}$.

\section{Extra-Chromosomal Complementations}

The coding regions of $c a r B, p q s C D E$, bioA, and $p u r F$ including 100 nucleotides upstream of the start codon were amplified by PCR from PA14 genomic DNA using the primers listed in Table 2 and following the same PCR conditions as described above. PCR products were purified and cloned into vectors pIApX2 (pqsCDE, carB) or pMMB207 (purF, bioA; Morales et al., 1991; West et al., 1994; Table 1). $1.5 \mu \mathrm{g}$ of each vector and insert were digested with the appropriate restriction enzymes and buffers in a final volume of $25 \mu \mathrm{L}$ (Table 1). After purification on agarose gel (GeneJet Gel extraction kit, ThermoScientific), vectors and inserts were ligated (T4 DNA ligase, Promega). E. coli DH10B thermo-competent cells were transformed with the ligation mixture and transformants selected on LB plates supplemented with $100 \mu \mathrm{g} / \mathrm{mL}$ ampicillin (pqsCDE, carB) or $15 \mu \mathrm{g} / \mathrm{mL}$ chloramphenicol ( $p u r F$, bioA). The resulting plasmids $\mathrm{pCarB}$ and $\mathrm{pPqsCDE}$ were electroporated into the corresponding PA14 Tn-mutants and selected on LBagar plates supplemented with $200 \mu \mathrm{g} / \mathrm{mL}$ carbenicillin. Plasmids pPurF and pBioA were transferred into the corresponding PA14
Tn-mutants by triparental mating using pRK2013 as a helper plasmid (Figurski and Helinski, 1979). Transconjugants were selected on LB-agar plates supplemented with $250 \mu \mathrm{g} / \mathrm{mL}$ chloramphenicol and $25 \mu \mathrm{g} / \mathrm{mL}$ gentamycin to counterselect E. coli donor strains.

\section{Construction of the $P$. aeruginosa las $A$ Mutant}

A las A deletion mutant was constructed by homologous recombination using plasmid pME3087 (Voisard et al., 2007). For the $5^{\prime}$-region PCR fragment, we used dNTP (0.2 $\mathrm{mM}$ final), Taq Buffer (1X final, Sigma), DMSO (5\% final), Taq polymerase (2.5 U/reaction), and $4 \mu \mathrm{L}$ of PA14 lysate. PCR conditions were as follows: one cycle of $2 \mathrm{~min}$ at $95^{\circ} \mathrm{C}, 27$ cycles of $20 \mathrm{~s}$ at $95^{\circ} \mathrm{C}$, $30 \mathrm{~s}$ at $57^{\circ} \mathrm{C}, 1 \mathrm{~min}$ at $72^{\circ} \mathrm{C}$ followed by a final extension of $4 \mathrm{~min}$ at $72^{\circ} \mathrm{C}$. For the $3^{\prime}$-region PCR fragment, we used dNTP $(0.2 \mathrm{mM}$ final), PFU Buffer (1X final), DMSO ( $5 \%$ final), PFU polymerase (2.5 U/reaction), and $4 \mu \mathrm{L}$ of PA14 bacterial lysate. PCR conditions were as follows: one cycle of $95^{\circ} \mathrm{C}$ for $2 \mathrm{~min}, 30$ cycles of $20 \mathrm{~s}$ at $95^{\circ} \mathrm{C}, 30 \mathrm{~s}$ at $55^{\circ} \mathrm{C}, 1 \mathrm{~min}$ at $72^{\circ} \mathrm{C}$, followed by a final extension of $4 \mathrm{~min}$ at $72^{\circ} \mathrm{C}$. The $5^{\prime}$-region and the $3^{\prime}$ region fragments were digested with BamHI. Both fragments were ligated and PCR reamplified using primers LasAF-Eco and LasAR-Hind (Table 2). The generated $1.6 \mathrm{kbp}$ fragment was digested using EcoRI and HindIII restriction enzymes and cloned into plasmid pME3087. The resulting plasmid plasA1 was introduced into $E$. coli strain SM10lpir for subsequent conjugation into $P$. aeruginosa PA14. Transductants were selected on M9-agar plates supplemented with $25 \mu \mathrm{M}$ citrate and $1 \mathrm{mM} \mathrm{MgSO}_{4}$ and $75 \mu \mathrm{g} / \mathrm{mL}$ tetracycline (Tc). Individual colonies were repurified on LB-agar plates containing $75 \mu \mathrm{g} / \mathrm{mL}$ Tc. Putative las $R$ deletion mutants generated after the second recombination event were enriched by 
carbenicillin-treatment as described previously (Voisard et al., 2007). Surviving cells, which were Tc-susceptible were screened by PCR for loss of a $300 \mathrm{bp}$ fragment in the las $A$ gene. One of three clones was selected for further analysis.

\section{Inhibition and Lytic Activity of $P$. aeruginosa Supernatants on S. aureus}

We measured both inhibition of the $S$. aureus growth as well as lysis of $S$. aureus cells by $P$. aeruginosa supernatants.

The inhibition capacity of $P$. aeruginosa supernatants on $S$. aureus growth was tested in liquid. Overnight cultures of $P$. aeruginosa grown in $\mathrm{MH}$-broth were centrifuged and the resulted supernatants were filtered $(0.22 \mu \mathrm{m}$, Millipore). An overnight culture of $S$. aureus strain $\mathrm{COL}$ was adjusted to an $\mathrm{OD}_{600}$ of 0.1 in MH-broth. $100 \mu \mathrm{L}$ of this bacterial suspension was incubated with $100 \mu \mathrm{L}$ of $P$. aeruginosa supernatant. All mixtures were incubated in triplicate at $37^{\circ} \mathrm{C}$ with intermittent shaking and $\mathrm{OD}_{600}$ was recorded for $10 \mathrm{~h}$ in a plate reader (BioTek Synergy H1).

The lytic activity of $P$. aeruginosa overnight culture supernatants on $S$. aureus was tested on LB medium, supplemented or not with $1 \mathrm{mM}$ uracil. The overnight cultures of $P$. aeruginosa were adjusted to the same $\mathrm{OD}_{600}$ before pelleting cells by centrifugation $(6,000 \times g, 10 \mathrm{~min})$. Supernatants were filtered $(0.22 \mu \mathrm{m})$ and used immediately. An overnight culture of $S$. aureus strain COL was adjusted to $\mathrm{OD}_{600}=1$ in $0.02 \mathrm{M}$ Tris- $\mathrm{HCl} \mathrm{pH} 7.5$ and cells were inactivated by heating at $95^{\circ} \mathrm{C}$ for $10 \mathrm{~min}$. $100 \mu \mathrm{L}$ of the $S$. aureus bacterial suspension was incubated with $100 \mu \mathrm{L}$ of filtered $P$. aeruginosa supernatants. Mixtures were incubated at $37^{\circ} \mathrm{C}$ with intermittent shaking and $\mathrm{OD}_{600}$ was recorded during $8 \mathrm{~h}$ in a plate reader (BioTek Synergy H1).

\section{Quantification of PQS Production}

To test whether $S$. aureus affects PQS production by $P$. aeruginosa, an overnight culture of $S$. aureus strain COL was adjusted to an $\mathrm{OD}_{600}=0.1$ in $\mathrm{LB}$ medium. $190 \mathrm{uL}$ of this dilution was deposited in a 96 well plate and incubated for $2 \mathrm{~h}$ without shaking. During this incubation, $P$. aeruginosa overnight cultures were centrifuged $(6,000 \mathrm{rpm}, 3 \mathrm{~min})$ and the pellet adjusted to an $\mathrm{OD}_{600}=2$ in $0.9 \% \mathrm{NaCl}$. $5 \mu \mathrm{L}$ of this cell suspensions of the $P$. aeruginosa PA14 and PA14 carB mutant were combined with $5 \mu \mathrm{L}$ of the cell suspension of the PQS-indicator strain PA14 $\Delta p q s A$ pqsA::lux culture (Fletcher et al., 2007) and added to the $190 \mu \mathrm{L}$ of the pre-incubated $S$. aureus cultures. The microtiter plate was incubated at $37^{\circ} \mathrm{C}$ with intermittent shaking and optical density at $600 \mathrm{~nm}$ and luminescence were recorded after $6 \mathrm{~h}$. Experiments were done in duplicate.

\section{Growth Competition Assay with Supernatants of Competitor Cultures}

Pseudomonas aeruginosa cultures were also spotted on $\mathrm{MH}$-plates seeded with $500 \mu \mathrm{l}$ of filtered supernatants from overnight competitor cultures. Overnight $(18 \mathrm{~h})$ cultures of competitor bacteria were centrifuged $10 \mathrm{~min}$ at $6,000 \mathrm{rpm}$. Supernatants were filtered $(0.22 \mu \mathrm{m})$ and $500 \mu \mathrm{L}$ of the filtrate was spread on agar plates. $P$. aeruginosa cultures were prepared as described above.

\section{Results}

\section{Generation of the $P$. aeruginosa PA14 Transposon Insertion Library and Selection of Mutants Affected in their Capacity to Compete with other Respiratory Pathogens}

We generated a library of 2,288 transposon insertion mutants in $P$. aeruginosa strain PA14. Three bacterial pathogens also commonly found in the lungs of CF patients were selected for the initial competition screening: $S$. aureus, B. cepacia, and $K$. pneumoniae. The PA14 mutant library was screened for: (i) an alteration of the inhibition zone produced by $P$. aeruginosa on a lawn of $S$. aureus (Figure 1A), and (ii) an alteration of $P$. aeruginosa growth in the presence of B. cepacia and K. pneumoniae (Figure 1B). Based on this screening, 64 mutants were retained displaying an altered inhibition zone (35 mutants) or growth (25 mutants) or both (4) in the presence of competitors when compared to wild-type PA14. Each of the selected mutants was re-tested in quadruplicates and four yielded reproducible phenotypes. Two mutants showed a reduction of the inhibition zone on a lawn of $S$. aureus, while the two others were affected in growth on lawns of $K$. pneumoniae or B. cepacia. Growth of these mutants was not affected on agar plates in the absence of competitors (data not shown).

\section{Role of the $P$ aeruginosa pqs Pathway During Competition with $S$. aureus}

We determined the transposon insertion site in the $P$. aeruginosa clone most affected in inhibition of $S$. aureus growth, by a two-step semi-random PCR. The transposon was inserted at nucleotide position 136 of the $p q s C$ gene, which belongs to the pqsABCDE operon (Xiao et al., 2006b). A pqsC mutant is deficient for the production of 4-hydroxy-2-alkylquinolines (HAQs; Dulcey et al., 2013). We complemented our pqsC transposon mutant by introducing a plasmid-encoded copy of the pqsCDE genes from PA14. The complemented mutant showed a partial restoration of the wild-type inhibition zone (Figure 2A). Because $p q s C$ is part of a multigene operon, we tested the phenotype of strains mutated in other genes belonging to the PQS biosynthesis pathway. As expected, PA14 derivatives mutated in $p q s A$ or $m v f R(p q s R)$, both deficient in HAQ biosynthesis, did not inhibit $S$. aureus growth (Figure 2A). The same phenotype was observed for the $p q s H$ mutant.

To test whether these phenotypes were limited to growth on solid medium, supernatants of $P$. aeruginosa overnight cultures were incubated together with a cell suspension of the $S$. aureus strain COL. Whereas supernatant of wild-type PA14 inhibited growth of $S$. aureus, supernatants from $p q s A, p q s C$, $m v f R$, and $p q s H$ mutants showed no inhibitory activity. In agreement with the data obtained on solid medium, the $p q s L$ mutant showed a partial inhibition of $S$. aureus growth in liquid medium (Figure 2B).

The LasA staphylolytic protease of $P$. aeruginosa cleaves the pentaglycine cross-links in the peptidoglycan of $S$. aureus leading to cell lysis (Kessler et al., 1993). We therefore tested the supernatant of a lasA mutant in competition with $S$. aureus, which did 
A

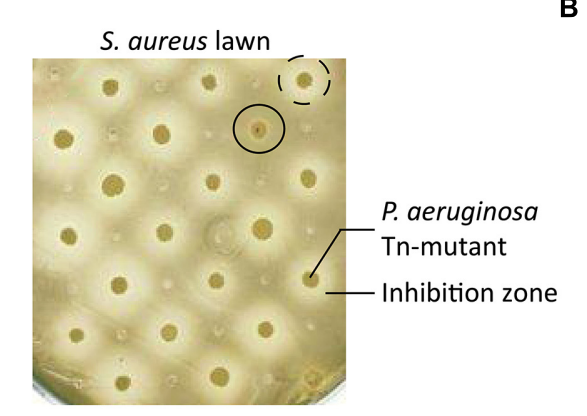

B

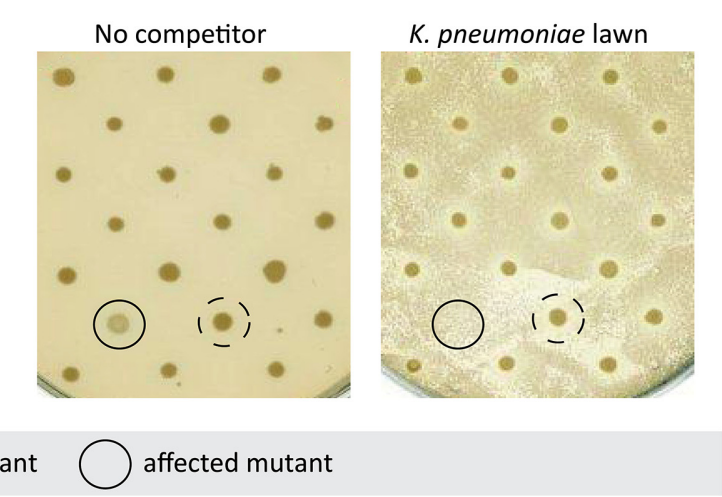

FIGURE 1 | Selection of Pseudomonas aeruginosa mutants affected in competition with bacterial pathogens. (A) P. aeruginosa

Tn-mutants were spotted on Staphylococcus aureus bacterial lawn on

$\mathrm{MH}$-agar plate. This panel shows an example of a mutant displaying an altered inhibition zone compared to the others, indicating that this mutant is not able to compete with $S$. aureus. (B) P. aeruginosa Tn-mutants were spotted on LB agar plate with or without Klebsiella pneumoniae. The unbroken line shows a mutant drastically affected by the presence of $K$. pneumoniae whereas it had a normal growth on plate without competitor. not alter the wild-type inhibition profile comparable to the one of the wild-type PA14 in our model (Figure 2B). These results demonstrate that the observed inhibition profile is not the consequence of the expression of LasA, but can be associated to the $p q s$ pathway activity in wild-type PA14. To further distinguish between inhibition and lytic activity, we performed the same experiment on heat-inactivated staphylococcal cells (Figure 2C). Optical density related to $S$. aureus cells rapidly decreased after addition of PA14 supernatants. We observed the same profile with the $p q s C$ mutant, indicating that HAQs do not contribute to $S$. aureus cell lysis but to growth inhibition. In contrast, PA14 $\Delta$ las $A$ was affected in its capacity to lyse $S$. aureus as expected from previous reports.

Because products of the PQS pathway are known to suppress growth in Gram-positive bacteria by inhibiting the respiratory chain in aerobic condition, we hypothesized that this phenotype may be abolished under hypoxic conditions. As expected, we observed no inhibition zone even for PA14 under hypoxic conditions (Figure 2D). Because nitrate is a key compound for the growth of $P$. aeruginosa under hypoxic conditions, we performed the experiment without and with addition of $\mathrm{KNO}_{3}$ as terminal electron acceptor. However, addition of $\mathrm{KNO}_{3}$ had no effect on the phenotype. This suggests that HAQs are unlikely to play a role in $S$. aureus growth inhibition under hypoxic conditions.

Taken together our experiments suggest that the las $A$ gene product is responsible for the lytic activity of $P$. aeruginosa, while HAQs are responsible for growth inhibition of $S$. aureus under aerobic conditions.

\section{Impact of the carB Mutation During Direct Competition between $P$. aeruginosa and}

\section{S. aureus}

The second mutant affected in its capacity to inhibit growth, and therefore to compete with $S$. aureus, harbored the transposon inserted at position 1,632 of the carB gene (PA14_62910), encoding the large subunit of the carbamoyl phosphate synthase (Winsor et al., 2011). CarB is involved in the pyrimidine pathway leading to uracil synthesis. Indeed, supplementation with uracil restored growth of the $c a r B$ mutant, but not the $S$. aureus growth inhibition (Figure 3A). Recently, pyrF, another gene required for uracil and pyrimidine synthesis was shown to affect the quorum-sensing (QS)-circuit in strain PA14 (Ueda et al., 2009). We therefore tested the QS-dependent virulence factor production in the $c a r B$ mutant. However, we observed no difference in rhamnolipid (Figure 3B) and elastase production (Figure 3C) between the carB mutant and the wild-type PA14. To determine if the effect observed with the $\operatorname{car} B$ mutant during competition with $S$. aureus was due to an alteration of the $p q s$ pathway we measured the production of PQS by quantifying luminescence produced by the PAO1 $\Delta p q s A p q s A:: l u x$ reporter strain. The quantity of luminescence produced was identical between the $\operatorname{car} B$ mutant and the wild-type PA14 strain, indicating that $c a r B$ does not affect the PQS production (Figure 3D) during competition with $S$. aureus. These results suggest that $\operatorname{car} B$ is required for inhibition of $S$. aureus growth, through a QS-independent mechanism.

\section{Role of the carB Gene During Competition between $P$. aeruginosa, $B$. cepacia, and K. pneumoniae}

Two transposon mutants of $P$. aeruginosa were affected in their growth in the presence of B. cepacia and K. pneumoniae as competitors. One of these mutants was the $c a r B$ mutant described above. This growth defect was complemented by the addition of a plasmid-encoded copy of $\operatorname{carB}$, as well as by the addition of uracil (Figure 4A). Remarkably, growth of the $c a r B$ mutant was not affected when competing with E. coli and S. epidermidis (data not shown). In contrast the addition of arginine alone, the second final product of this metabolic pathway (Figure 5), had no impact on the growth of the $c a r B$ mutant (Figure 4B). To determine whether soluble factors secreted by the competitors could be involved, we plated supernatants of bacterial competitors on 
A

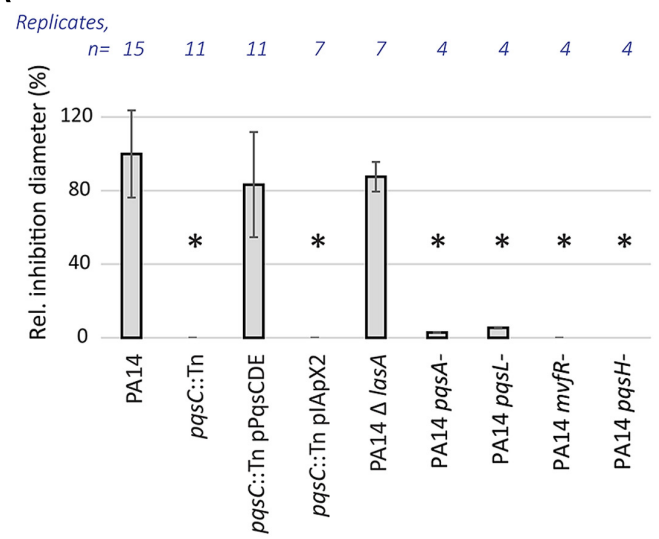

B

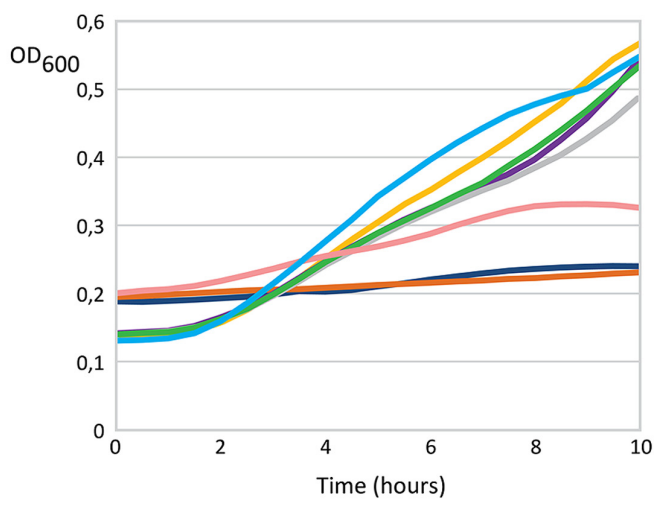

$$
\begin{array}{rlr}
\text { Supernatants: } & - \text { PA14 } & -p q s C:: T n \\
& - \text { PA14 } \triangle \text { lasA } & - \text { PA14 mvfR- } \\
& - \text { PA14 pqsA- } & - \text { PA14 pqsH- } \\
& - \text { PA14 pqsL- } & - \text { without supernatant }
\end{array}
$$

C

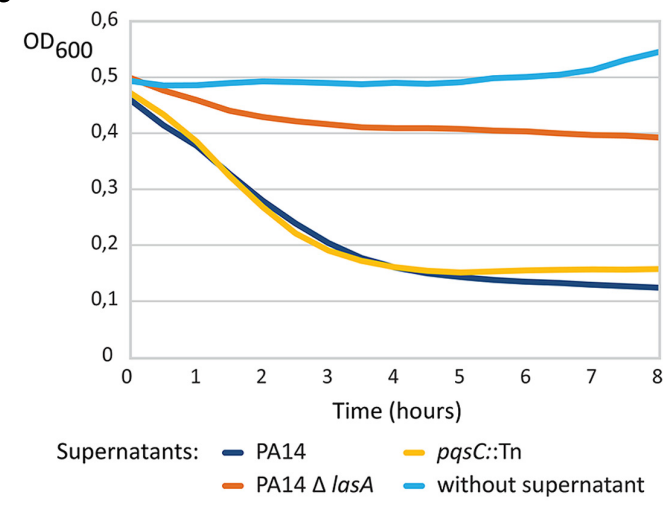

D

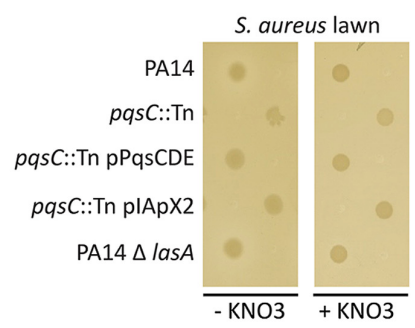

FIGURE 2 | Continued

\section{FIGURE 2 | Continued}

Role of the pqs pathway of $P$. aeruginosa in direct competition with S. aureus. (A) Effect of pqs $C$ disruption on the inhibition of $S$. aureus growth. Spots of $P$. aeruginosa cultures were deposited on LB agar plates seeded with a lawn of $S$. aureus strain COL. Inhibition zone diameters were measured, normalized against the diameter of the corresponding spots and expressed as a percentage against the wild-type PA14 values. Error bars are standard deviations calculated on at least four replicates. Statistical significance was determined by using a $t$-test with unequal variances $\left({ }^{*} p<0.01\right)$. (B) Inhibition activity of $P$. aeruginosa supernatants on $S$. aureus growth. Supernatants of $P$. aeruginosa overnight cultures were incorporated on $S$. aureus cells. $S$. aureus growth $\left(\mathrm{OD}_{600}\right)$ was monitored during $10 \mathrm{~h}$ at $37^{\circ} \mathrm{C}$ in presence to these supernatants. (C) Lytic activity of $P$. aeruginosa supernatants on inactivated $S$. aureus cells. Supernatants of $P$. aeruginosa overnight cultures were incorporated on heat-inactivated $S$. aureus cells. $\mathrm{OD}_{600}$ was monitored during $8 \mathrm{~h}$ at $37^{\circ} \mathrm{C}$ in presence to these supernatants to evaluate $S$. aureus lysis. (D) Role of the pqs pathway in hypoxic conditions. Spots of $P$. aeruginosa cultures were deposited on LB agar plates cover by a $S$. aureus lawn. Plates were incubated during $48 \mathrm{~h}$ in hypoxic conditions.

LB-agar plates prior to $P$. aeruginosa spotting. Culture supernatants of $B$. cepacia and $K$. pneumoniae did not affect the growth of the $\operatorname{car} B$ mutant, suggesting that the presence of metabolically active competing bacteria is required to repress growth of this mutant (Figure 4A). Taken together, these data demonstrate that the $c a r B$ gene, and by analogy the uracil/pyrimidine biosynthesis, is an essential metabolic pathway for the competition of $P$. aeruginosa against $B$. cepacia, $K$. pneumoniae, and $S$. aureus.

\section{Effect of the purF Mutation on the $P$. aeruginosa Growth in Presence of $B$. cepacia, K. pneumoniae, and E. coli}

The second mutant with a growth defect in the presence of competitors had the transposon inserted at position 264 of the purF (PA14_23920) gene, encoding an amidophosphoribosyl transferase. This protein is a key enzyme of purine metabolism, supplying nucleotides for DNA and RNA synthesis (Sampei and Mizobuchi, 1988). The purF::Tn mutant did not grow when cells were spotted on plates containing lawns of B. cepacia, $K$. pneumoniae, and E. coli (Figure 4C). This alteration was complemented by the addition of a plasmid-encoded copy of the purF gene. In contrast, the purF mutant showed normal growth in the presence of S. epidermidis and S. aureus (data not shown). As observed above for the carB mutant, culture supernatants of competing bacteria did not affect growth of the purF-disrupted strain (Figure 4C). This suggests that the purF gene is essential for $P$. aeruginosa growth in presence of the B. cepacia, K. pneumoniae, and E. coli.

\section{Role of the Biotin Synthesis Pathway on Beneficial Interactions between $P$. aeruginosa and other Respiratory Pathogens}

To determine if growth of $P$. aeruginosa can be promoted by the presence of other bacterial pathogens, we screened the transposon library for mutants that grew better in the presence of 
a competitor than in its absence on rich medium. We identified one transposon mutant that grew poorly on $\mathrm{MH}$-agar, but showed wild-type growth in the presence of K. pneumoniae and E. coli (Figure 4D). This growth "enhancement" was not seen in the presence of B. cepacia, S. epidermidis, and $S$. aureus bacterial lawns (data not shown). We identified the transposon insertion in this mutant at position 474 of the bio $A$ (PA14_05460) gene, encoding an adenosylmethionine-8-amino7-oxononanoate aminotransferase, involved in the biotin biosynthesis pathway (Stoner and Eisenberg, 1975). Indeed the addition of biotin, as well as extra-chromosomic complementation with the bioA gene, restored growth of the bioA-disrupted mutant (Figure 4D). Finally, growth of the bio $A$ transposon mutant was not restored by supernatants of $K$. pneumoniae and $E$. coli, suggesting that the presence of metabolically active cells of these organisms is required to complement the growth deficit (Figure 4D).

\section{Discussion}

Our study identified metabolic pathways involved in either detrimental or beneficial interactions between $P$. aeruginosa and four bacterial respiratory pathogens. By screening a transposon library of 2,288 mutants in PA14, we identified mutants displaying altered growth inhibition, or growth phenotypes in the presence of co-colonizing bacterial species. We found that both $p q s C$ and $\operatorname{car} B$, responsible, respectively, for HAQ and uracil/pyrimidine synthesis, play an essential role in the direct competition of $P$. aeruginosa with $S$. aureus. Secondly, we identified $\operatorname{car} B$ and purF, the latter involved in purine synthesis, as essential for exploitative competition against $K$. pneumoniae and B. cenocepacia (Figure 5). Finally, we found that co-colonizing strains may also have beneficial effects, as illustrated by growth restoration of the P. aeruginosa bioA mutant by K. pneumoniae and E. coli (Figure 5).

Studies on microbial interactions have already revealed the role of the Pseudomonas quinolone signal (PQS) biosynthesis pathway in the inhibition of $S$. aureus growth. It has been demonstrated that 2-heptyl-4-quinolone $N$-oxide (HQNO), one of the final products of the pqs pathway, suppresses growth of Grampositive bacteria, but not of Gram-negative bacteria (Machan et al., 1992). In aerobic conditions, HQNO binds to quinonereacting cytochromes and inhibits respiratory electron transfer from quinone to cytochromes (Magalon et al., 1998; Toyofuku et al., 2008). The present study confirms the role of the PQSbiosynthesis pathway in the direct competition with $S$. aureus. Indeed, $p q s C$ acts at the beginning of the metabolic PQS-pathway and its inactivation leads to the absence of all HAQs including PQS, 2-heptyl-4-quinolone (HHQ), as well as their N-oxide derivatives. The $p q s C$ mutant identified in our screening was unable to inhibit growth of $S$. aureus in rich medium. The wildtype phenotype was partially restored in the $p q s C$ mutant by complementation with plasmid-encoded copies of the pqsCDE genes. The partial complementation can be explained by a gene dosage effect due to overexpression from the constitutive promoter present on the vector plasmid pIApX2. In addition, we

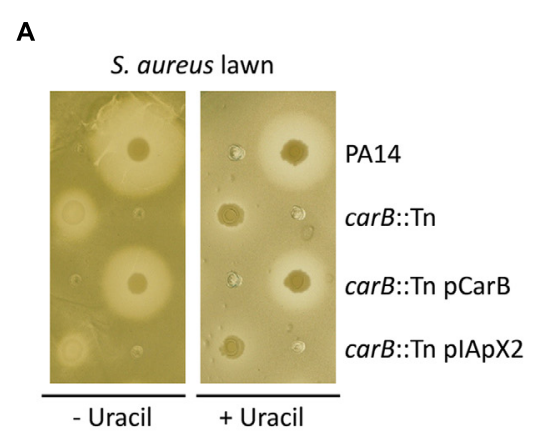

B

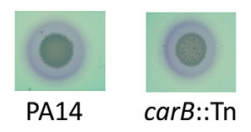

C

$\mathrm{OD}_{495} / \mathrm{OD}_{600}$

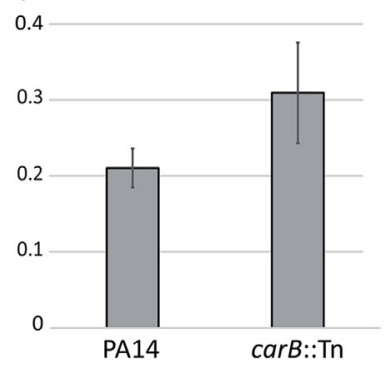

D

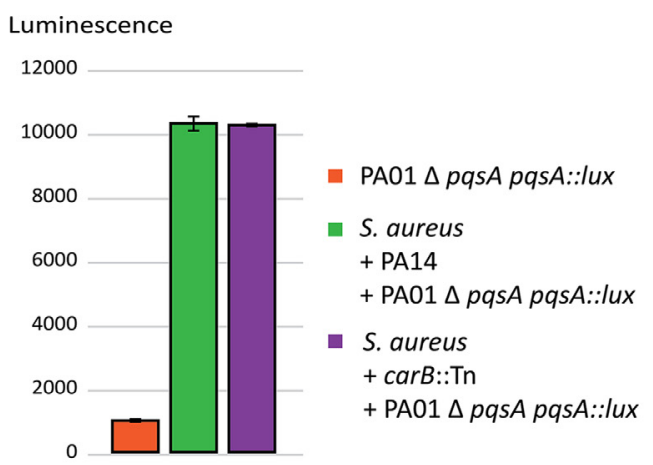

FIGURE 3 | Role of the $P$. aeruginosa carB gene during competition with S. aureus. (A) Spots of $P$. aeruginosa cultures were deposited on $L B$ agar plates seeded with a lawn of $S$. aureus strain COL. (B) Rhamnolipid production by the wild-type PA14 and the carB-disrupted PA14 strains. No difference was observed between the two strains within duplicates indicating that the Rhl quorum-sensing (QS) is not affected in the mutant. (C) Elastase production by the wild-type PA14 and the carB-disrupted PA14. Error bars indicate standard deviations calculated from three experimental replicates. (D) Quantification of PQS production during competition with S. aureus. The carB mutant and the wild-type PA14 strains were both incubated with the competitor and with the PAO1 $\triangle$ pqsA pqsA://ux reporter strain. PQS production was evaluated by quantification of the luminescence produced by the reporter strain in response to the amount of PQS in the medium. Luminescence was quantified after $6 \mathrm{~h}$ of incubation at $37^{\circ} \mathrm{C}$. Error bars are standard deviations calculated on duplicate. 
A

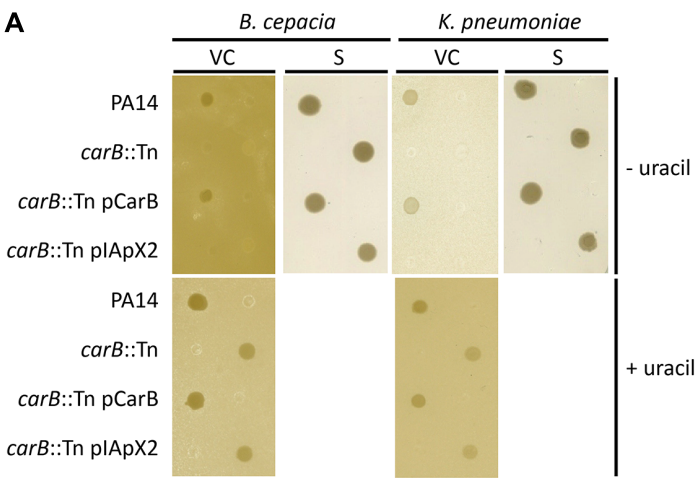

C

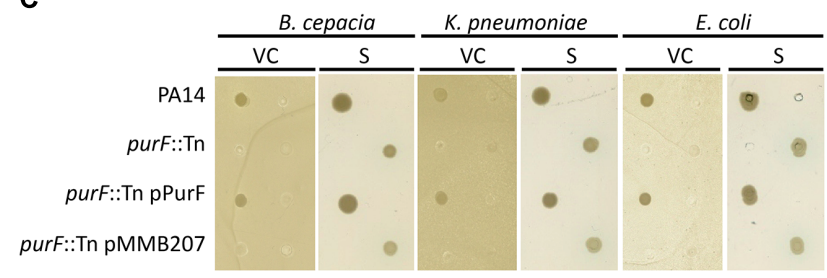

FIGURE 4 | Role of the carB, purF and bioA mutations during bacterial interactions between $P$. aeruginosa and other respiratory pathogens.

(A-D) Spots of $P$. aeruginosa cultures were deposited on $L B$ agar $(\mathbf{A}, \mathbf{B})$ or $\mathrm{MH}$
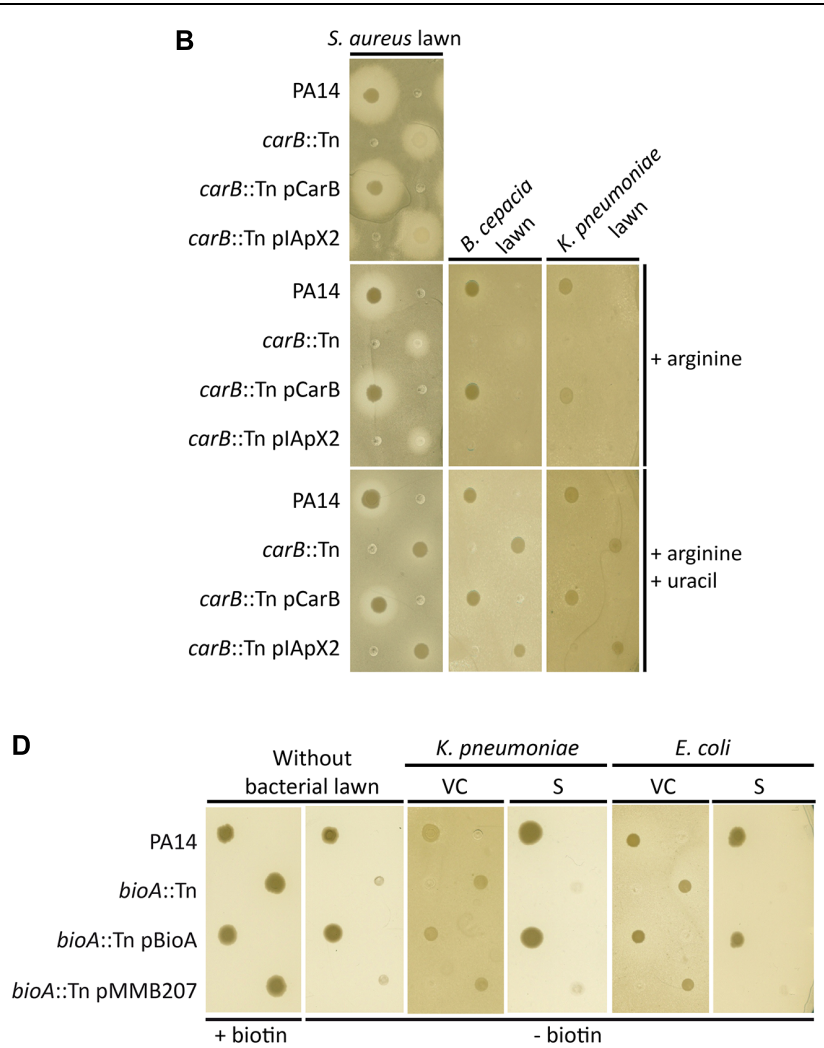

agar plates (C,D) seeded with a lawn of $S$. aureus, K. pneumoniae, B. cenocepacia, or E. coli. Bacterial lawns were composed by viable cells (VC) from overnight cultures or by supernatants (S) of filtrated overnight cultures. demonstrated that the PQS-pathway does not play a role under hypoxic conditions. This result was not unexpected since under hypoxic conditions, the aerobic respiratory chain is not functional and cannot be inhibited by HQNO (Machan et al., 1992). Furthermore, HQNO and PQS seem to be produced only under aerobic conditions due to the oxygen requirement of the $\mathrm{PqsH}$ mono-oxygenase to catalyze the final conversion of HHQ to PQS (Schertzer et al., 2010). This suggests that in the thickened mucous layers in the airways of CF patients, where low oxygen concentrations are prevailing (Worlitzsch et al., 2002), HQNO may play only a limited role in interference between $P$. aeruginosa and $S$. aureus. We can also hypothesize that the role of the PQS-system on S. aureus is limited in mixed biofilms, representing microaerophilic growth conditions. Nevertheless, HHQ and PQS were identified in sputum samples from CF patients (Collier et al., 2002; Palmer et al., 2005) indicating that maybe, in the more oxygenated upper respiratory tract, HQNO might play a more prominent role in growth inhibition of Gram-positive bacteria.

Our results further suggest that the $\mathrm{N}$-oxide derivatives of HAQs are responsible primarily for the $S$. aureus growth inhibition. As described above, the $p q s H$ mutant was affected in the conversion of HHQ to PQS. PQS contributes to the positive feedback regulation of the pqsA-D genes via PqsR. Thus, a defect in PQS production should lead to the absence (or major decrease) of HHQ and HQNO in a $p q s H$ mutant. In addition our results showed a small residual activity of the $p q s L$ mutant, which displayed only a weak inhibition of $S$. aureus growth both on agar and in liquid. PqsL is a putative mono-oxygenase converting HHQ to HQNO, and PQS to its N-oxide derivative (Lepine et al., 2004). A pqsL mutant was shown to produce increased amounts of PQS (D’Argenio et al., 2002), and maybe also of other HAQs, suggesting that the non- $N$-oxide derivatives may also display a weak growth inhibitory effect on $S$. aureus.

In addition to the role of PQS, we demonstrated that the $P$. aeruginosa carB gene is required for direct competition with $S$. aureus. Without uracil, the carB-disrupted strain exhibited an alteration in its capacity to inhibit $S$. aureus growth. However, the growth of this mutant appeared to be slightly affected. Nevertheless, when we added uracil in the medium, the growth of the carB-disrupted strain was totally restored, but the inhibition of $S$. aureus growth was still diminished. Previous reports suggested that uracil influences all three QS-systems in $P$. aeruginosa (i.e., las, rhl, pqs; Ueda et al., 2009). Since uracil is the final product of the biosynthesis pathway containing the $\operatorname{car} B$ gene, we tested if the phenotype exhibited by the carB-disrupted strain can be linked to QS. However, phenotypic analysis of QS-dependent traits showed that none of the three QS-systems was affected in the carB-disrupted strain. This 


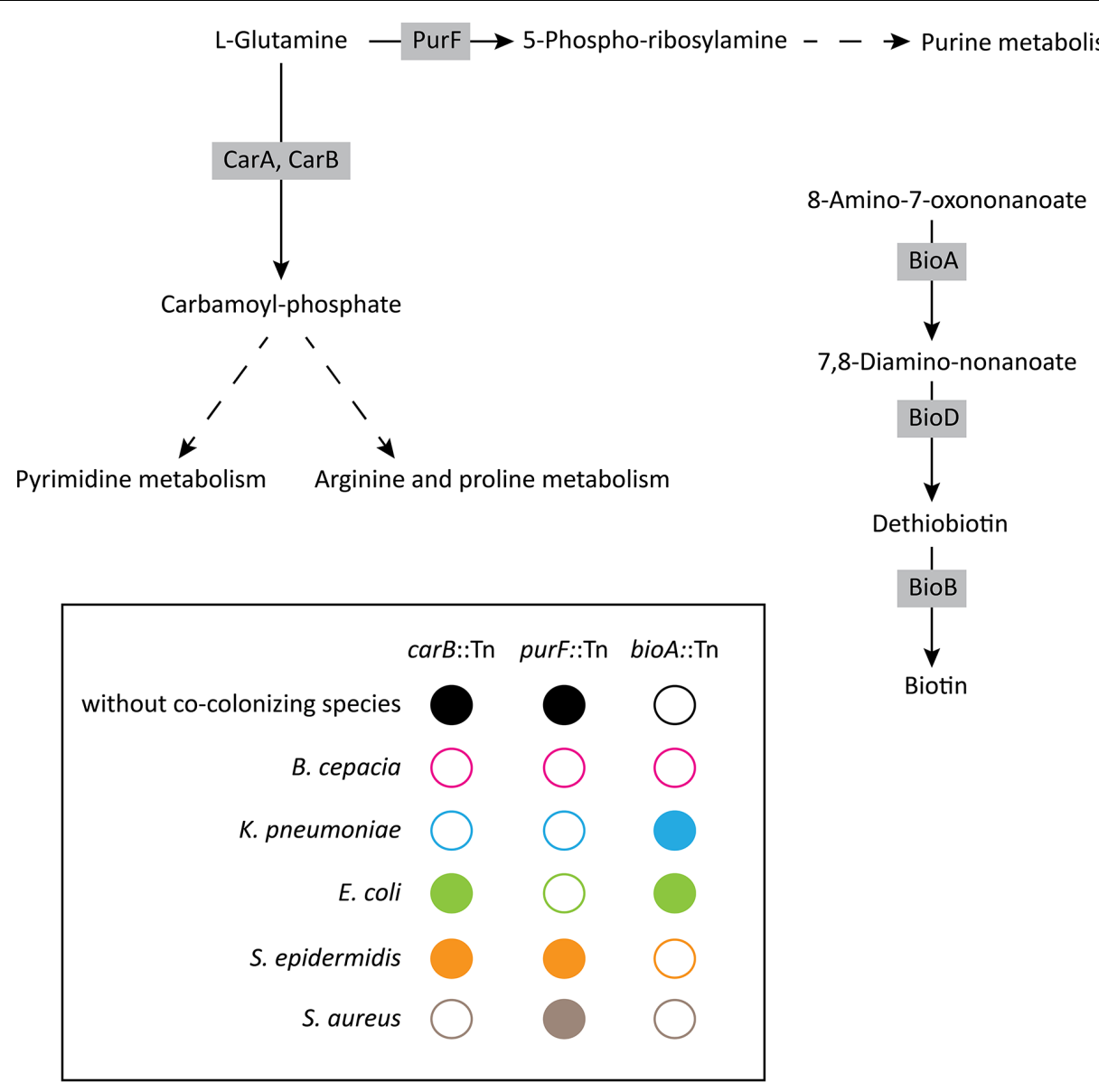

FIGURE 5 | Schematic summary of the growth phenotypes displayed by the carB, purF, and bioA mutants during interactions with other respiratory pathogens. Metabolic pathways are based on the Kyoto Encyclopedia of Genes and Genomes databases. Open circles represent no growth, whereas filled circles indicate growth of $P$. aeruginosa mutants.

indicates that a QS-unrelated mechanism was responsible for reduced inhibition of $S$. aureus growth in the carB-disrupted strain.

Interestingly, the carB gene also appeared essential for the exploitative competition between $P$. aeruginosa and $S$. aureus, as well as with $B$. cepacia and $K$. pneumoniae. These results suggest that $\operatorname{car} B$ is involved in the competition for resources between $P$. aeruginosa and these three competitors. CarB is an enzyme catalyzing the transformation of L-glutamine into carbamoyl-phosphate, an intermediate in the pyrimidine, arginine, and proline metabolisms (Figure 5). We show that the phenotype of the carB-disrupted strain can be restored by the addition of uracil, but not of arginine, demonstrating that the role of the $\operatorname{car} B$ gene in the exploitative competition can be associated to the pyrimidine biosynthesis pathway.

In addition to $\operatorname{car} B$, the purF gene also appeared to be an essential gene for exploitative competition. Interestingly, growth of the purF mutant was not affected in the presence of Gram-positive bacteria (S. aureus and $S$. epidermidis) but was severely affected in grow in the presence of the
Gram-negative strains tested (B. cenocepacia, K. pneumoniae, $E$. coli). The purF gene encodes an amidophosphoribosyltransferase involved in the conversion of L-Glutamine into 5-Phospho-ribosylamine, a primary product of the purine metabolism (Figure 5). Taken together, these results highlight the essential role of nucleic acid biosynthesis pathways for exploitative competition. Interestingly, the purine and pyrimidine synthesis pathways were also shown to be important for colonization of the mouse intestine by $E$. coli (Vogel-Scheel et al., 2010), an environment where invading organisms have to compete with resident microbial flora.

Finally, we identified beneficial interactions between $P$. aeruginosa and other lung co-colonizing species via the biotin synthesis pathway. Whereas a $P$. aeruginosa bioA-disrupted mutant was unable to grow on rich medium, the presence of $K$. pneumoniae and E. coli complemented the growth defect of this strain (Figure 5). In other words, the presence of K. pneumoniae and $E$. coli can be beneficial to $P$. aeruginosa when biotin supply is limited. However, the molecular basis of this beneficial interaction remains to be elucidated. 


\section{Conclusion}

Understanding the interactions between the various bacterial communities colonizing the CF-airways is of considerable importance as interactions can potentially affect the metabolism of pathogens, alter the population structure and eventually influence disease progression. It is clear from our experiments that complex interactions take place between CF-lung colonizing species which may lead to profound changes in bacterial community structures in CF-patients. Detrimental and beneficial interactions not only modulate the richness and the diversity of species but also create a complex environment in which bacterial species need to adapt to co-colonizing species aiming to increase their relative fitness. The metabolic pathways involved in these

\section{References}

Basler, M., Ho, B. T., and Mekalanos, J. J. (2013). Tit-for-tat: type VI secretion system counterattack during bacterial cell-cell interactions. Cell 152, 884-894. doi: 10.1016/j.cell.2013.01.042

Boon, E., Meehan, C. J., Whidden, C., Wong, D. H., Langille, M. G., and Beiko, R. G. (2014). Interactions in the microbiome: communities of organisms and communities of genes. FEMS Microbiol. Rev. 38, 90-118. doi: 10.1111/15746976.12035

Bragonzi, A., Farulla, I., Paroni, M., Twomey, K. B., Pirone, L., Lorè, N. I., et al. (2012). Modelling co-infection of the cystic fibrosis lung by Pseudomonas aeruginosa and Burkholderia cenocepacia reveals influences on biofilm formation and host response. PLoS ONE 7:e52330. doi: 10.1371/journal.pone. 0052330

Cao, H., Krishnan, G., Goumnerov, B., Tsongalis, J., Tompkins, R., and Rahme, L. G. (2001). A quorum sensing-associated virulence gene of Pseudomonas aeruginosa encodes a LysR-like transcription regulator with a unique selfregulatory mechanism. Proc. Natl. Acad. Sci. U.S.A. 98, 14613-14618. doi: 10.1073/pnas.251465298

Cardozo, V. F., Oliveira, A. G., Nishio, E. K., Perugini, M. R., Andrade, C. G., Silveira, W. D., et al. (2013). Antibacterial activity of extracellular compounds produced by a Pseudomonas strain against methicillin-resistant Staphylococcus aureus (MRSA) strains. Ann. Clin. Microbiol. Antimicrob. 12:12. doi: 10.1186/1476-0711-12-12

Collier, D. N., Anderson, L., Mcknight, S. L., Noah, T. L., Knowles, M., Boucher, R., et al. (2002). A bacterial cell to cell signal in the lungs of cystic fibrosis patients. FEMS Microbiol. Lett. 215, 41-46. doi: 10.1111/j.1574-6968.2002. tb11367.x

Cornforth, D. M., and Foster, K. R. (2013). Competition sensing: the social side of bacterial stress responses. Nat. Rev. Microbiol. 11, 285-293. doi: 10.1038/nrmicro2977

Cox, M. J., Allgaier, M., Taylor, B., Baek, M. S., Huang, Y. J., Daly, R. A., et al. (2010). Airway microbiota and pathogen abundance in age-stratified cystic fibrosis patients. PLOS ONE 5:e11044. doi: 10.1371/journal.pone. 0011044

D’Argenio, D. A., Calfee, M. W., Rainey, P. B., and Pesci, E. C. (2002). Autolysis and autoaggregation in Pseudomonas aeruginosa colony morphology mutants. J. Bacteriol. 184, 6481-6489. doi: 10.1128/JB.184.23.6481-64 89.2002

Deziel, E., Lepine, F., Milot, S., He, J., Mindrinos, M. N., Tompkins, R. G., et al. (2004). Analysis of Pseudomonas aeruginosa 4-hydroxy-2alkylquinolines (HAQs) reveals a role for 4-hydroxy-2-heptylquinoline in cell-to-cell communication. Proc. Natl. Acad. Sci. U.S.A. 101, 1339-1344. doi: 10.1073/pnas.0307694100

Duan, K., Dammel, C., Stein, J., Rabin, H., and Surette, M. G. (2003). Modulation of Pseudomonas aeruginosa gene expression by host microflora through interspecies communication. Mol. Microbiol. 50, 1477-1491. doi: 10.1046/j.13652958.2003.03803.x complex interactions could potentially be exploited to manipulate microbial population structure to improve the clinical outcome of chronic infectious.

\section{Acknowledgments}

This work was supported by grants No. 32473B-140929 from the Swiss National Science Foundation and No. 146670301 from the Roche Organ Transplantation Research Foundation. The authors are grateful to Prof. Laurence Rahme (Harvard Medical School, USA) and Dr. Yok Ai Que (CHUV, Lausanne, Switzerland) for the PA14 $m v f R^{-}$, PA14 $p q s L^{-}$, PA14 $p q s A^{-}$, PA14 $p q s H^{-}$ mutants.

Dulcey, C. E., Dekimpe, V., Fauvelle, D. A., Milot, S., Groleau, M. C., Doucet, N. et al. (2013). The end of an old hypothesis: the pseudomonas signaling molecules 4-hydroxy-2-alkylquinolines derive from fatty acids, not 3ketofatty acids. Chem. Biol. 20, 1481-1491. doi: 10.1016/j.chembiol.2013. 09.021

Dyke, K. G., Jevons, M. P., and Parker, M. T. (1966). Penicillinase production and intrinsic resistance to penicillins in Staphylococcus aureus. Lancet 1, 835-838. doi: 10.1016/S0140-6736(66)90182-6

Essar, D. W., Eberly, L., Hadero, A., and Crawford, I. P. (1990). Identification and characterization of genes for a second anthranilate synthase in Pseudomonas aeruginosa: interchangeability of the two anthranilate synthases and evolutionary implications. J. Bacteriol. 172, 884-900.

Figurski, D. H., and Helinski, D. R. (1979). Replication of an origin-containing derivative of plasmid RK2 dependent on a plasmid function provided in trans. Proc. Natl. Acad. Sci. U.S.A. 76, 1648-1652. doi: 10.1073/pnas.76. 4.1648

Fletcher, M. P., Diggle, S. P., Camara, M., and Williams, P. (2007). Biosensorbased assays for PQS, HHQ and related 2-alkyl-4-quinolone quorum sensing signal molecules. Nat. Protoc. 2, 1254-1262. doi: 10.1038/nprot. 2007.158

Folkesson, A., Jelsbak, L., Yang, L., Johansen, H. K., Ciofu, O., Hoiby, N., et al. (2012). Adaptation of Pseudomonas aeruginosa to the cystic fibrosis airway: an evolutionary perspective. Nat. Rev. Microbiol. 10, 841-851. doi: 10.1038/nrmicro2907

Friedman, L., and Kolter, R. (2004). Genes involved in matrix formation in Pseudomonas aeruginosa PA14 biofilms. Mol. Microbiol. 51, 675-690. doi: 10.1046/j.1365-2958.2003.03877.x

Goss, C. H., and Burns, J. L. (2007). Exacerbations in cystic fibrosis. 1: epidemiology and pathogenesis. Thorax 62, 360-367. doi: 10.1136/thx.2006.060889

Hoffman, L. R., Deziel, E., D’argenio, D. A., Lepine, F., Emerson, J., Mcnamara, S., et al. (2006). Selection for Staphylococcus aureus small-colony variants due to growth in the presence of Pseudomonas aeruginosa. Proc. Natl. Acad. Sci. U.S.A. 103, 19890-19895. doi: 10.1073/pnas.0606756104

Kessler, E., Safrin, M., Olson, J. C., and Ohman, D. E. (1993). Secreted LasA of Pseudomonas aeruginosa is a staphylolytic protease. J. Biol. Chem. 268, 7503-7508.

Kohler, T., Curty, L. K., Barja, F., Van Delden, C., and Pechere, J. C. (2000). Swarming of Pseudomonas aeruginosa is dependent on cell-to-cell signaling and requires flagella and pili. J. Bacteriol. 182, 5990-5996. doi: 10.1128/JB.182.21.5990-5996.2000

Kulasekara, H. D., Ventre, I., Kulasekara, B. R., Lazdunski, A., Filloux, A., and Lory, S. (2005). A novel two-component system controls the expression of Pseudomonas aeruginosa fimbrial cup genes. Mol. Microbiol. 55, 368-380. doi: 10.1111/j.1365-2958.2004.04402.x

Lepine, F., Milot, S., Deziel, E., He, J., and Rahme, L. G. (2004). Electrospray/mass spectrometric identification and analysis of 4-hydroxy-2-alkylquinolines (HAQs) produced by Pseudomonas aeruginosa. J. Am. Soc. Mass Spectrom. 15, 862-869. doi: 10.1016/j.jasms.2004.02.012 
Lightbown, J. W., and Jackson, F. L. (1954). Inhibition of cytochrome system of heart muscle and of Staphylococcus aureus by 2-heptyl-4-hydroxyquinoline-Noxide, an antagonist of dihydrostreptomycin. Biochem. J. 58, xlix.

Lipuma, J. J. (2010). The changing microbial epidemiology in cystic fibrosis. Clin. Microbiol. Rev. 23, 299-323. doi: 10.1128/CMR. 00068-09

Machan, Z. A., Taylor, G. W., Pitt, T. L., Cole, P. J., and Wilson, R. (1992). 2-Heptyl-4-hydroxyquinoline $\mathrm{N}$-oxide, an antistaphylococcal agent produced by Pseudomonas aeruginosa. J. Antimicrob. Chemother. 30, 615-623. doi: $10.1093 / \mathrm{jac} / 30.5 .615$

Magalon, A., Rothery, R. A., Lemesle-Meunier, D., Frixon, C., Weiner, J. H., and Blasco, F. (1998). Inhibitor binding within the NarI subunit (cytochrome bnr) of Escherichia coli nitrate reductase A. J. Biol. Chem. 273, 10851-10856. doi: 10.1074/jbc.273.18.10851

Mashburn, L. M., Jett, A. M., Akins, D. R., and Whiteley, M. (2005). Staphylococcus aureus serves as an iron source for Pseudomonas aeruginosa during in vivo coculture. J. Bacteriol. 187, 554-566. doi: 10.1128/JB.187.2.554566.2005

Morales, V. M., Backman, A., and Bagdasarian, M. (1991). A series of wide-hostrange low-copy-number vectors that allow direct screening for recombinants. Gene 97, 39-47. doi: 10.1016/0378-1119(91)90007-X

Palmer, K. L., Mashburn, L. M., Singh, P. K., and Whiteley, M. (2005). Cystic fibrosis sputum supports growth and cues key aspects of Pseudomonas aeruginosa physiology. J. Bacteriol. 187, 5267-5277. doi: 10.1128/JB.187.15.5267-52 77.2005

Pearson, J. P., Pesci, E. C., and Iglewski, B. H. (1997). Roles of Pseudomonas aeruginosa las and rhl quorum-sensing systems in control of elastase and rhamnolipid biosynthesis genes. J. Bacteriol. 179, 5756-5767.

Pukatzki, S., Ma, A. T., Sturtevant, D., Krastins, B., Sarracino, D., Nelson, W. C., et al. (2006). Identification of a conserved bacterial protein secretion system in Vibrio cholerae using the Dictyostelium host model system. Proc. Natl. Acad. Sci. U.S.A. 103, 1528-1533. doi: 10.1073/pnas.0510 322103

Rahme, L. G., Stevens, E. J., Wolfort, S. F., Shao, J., Tompkins, R. G., and Ausubel, F. M. (1995). Common virulence factors for bacterial pathogenicity in plants and animals. Science 268, 1899-1902. doi: 10.1126/science. 7604262

Sampei, G., and Mizobuchi, K. (1988). Nucleotide sequence of the Escherichia coli purF gene encoding amidophosphoribosyltransferase for de novo purine nucleotide synthesis. Nucleic Acids Res. 16:8717. doi: 10.1093/nar/16.17.8717

Schertzer, J. W., Brown, S. A., and Whiteley, M. (2010). Oxygen levels rapidly modulate Pseudomonas aeruginosa social behaviours via substrate limitation of PqsH. Mol. Microbiol. 77, 1527-1538. doi: 10.1111/j.1365-2958.2010.07303.x

Simon, R., Priefer, U., and Puhler, A. (1983). A broad host range mobilization system for in vivo genetic engineering: transposon mutagenesis in Gram negative bacteria. Nat. Biotechnol. 1, 784-791. doi: 10.1038/nbt1183-784

Stoner, G. L., and Eisenberg, M. A. (1975). Purification and properties of 7, 8-diaminopelargonic acid aminotransferase. J. Biol. Chem. 250, 4029-4036.

Toder, D. S., Ferrell, S. J., Nezezon, J. L., Rust, L., and Iglewski, B. H. (1994). lasA and lasB genes of Pseudomonas aeruginosa : analysis of transcription and gene product activity. Infect. Immun. 62, 1320-1327.
Toyofuku, M., Nomura, N., Kuno, E., Tashiro, Y., Nakajima, T., and Uchiyama, H. (2008). Influence of the Pseudomonas quinolone signal on denitrification in Pseudomonas aeruginosa. J. Bacteriol. 190, 7947-7956. doi: 10.1128/JB. 00968-08

Ueda, A., Attila, C., Whiteley, M., and Wood, T. K. (2009). Uracil influences quorum sensing and biofilm formation in Pseudomonas aeruginosa and fluorouracil is an antagonist. Microb. Biotechnol. 2, 62-74. doi: 10.1111/j.17517915.2008.00060.x

Vogel-Scheel, J., Alpert, C., Engst, W., Loh, G., and Blaut, M. (2010). Requirement of purine and pyrimidine synthesis for colonization of the mouse intestine by Escherichia coli. Appl. Environ. Microbiol. 76, 5181-5187. doi: 10.1128/AEM.00242-10

Voisard, C., Bull, C. T., Keel, C., Laville, J., Maurhofer, M., Schnider, U., et al. (2007). "Biocontrol of root diseases by Pseudomonas fluorescens CHA0: current concepts and experimental approaches," in Molecular Ecology of Rhizosphere Microorganisms, eds F. O’Gara, D. N. Dowling, and I. B. Boesten (Weinheim: Wiley-VCH Verlag GmbH), 67-89.

West, S. E., Schweizer, H. P., Dall, C., Sample, A. K., and Runyen-Janecky, L. J. (1994). Construction of improved Escherichia-Pseudomonas shuttle vectors derived from pUC18/19 and sequence of the region required for their replication in Pseudomonas aeruginosa. Gene 148, 81-86. doi: 10.1016/03781119(94)90237-2

Winsor, G. L., Lam, D. K., Fleming, L., Lo, R., Whiteside, M. D., Yu, N. Y., et al. (2011). Pseudomonas genome database: improved comparative analysis and population genomics capability for Pseudomonas genomes. Nucleic Acids Res. 39, D596-D600. doi: 10.1093/nar/gkq869

Worlitzsch, D., Tarran, R., Ulrich, M., Schwab, U., Cekici, A., Meyer, K. C., et al. (2002). Effects of reduced mucus oxygen concentration in airway Pseudomonas infections of cystic fibrosis patients. J. Clin. Invest. 109, 317-325. doi: 10.1172/JCI13870

Xiao, G., DéZiel, E., He, J., LéPine, F., Lesic, B., Castonguay, M. H., et al. (2006a). MvfR, a key Pseudomonas aeruginosa pathogenicity LTTR-class regulatory protein, has dual ligands. Mol. Microbiol. 62, 1689-1699. doi: 10.1111/j.13652958.2006.05462.x

Xiao, G., He, J., and Rahme, L. G. (2006b). Mutation analysis of the Pseudomonas aeruginosa mvfR and pqsABCDE gene promoters demonstrates complex quorum-sensing circuitry. Microbiology 152, 1679-1686. doi: $10.1099 / \mathrm{mic} .0 .28605-0$

Conflict of Interest Statement: The authors declare that the research was conducted in the absence of any commercial or financial relationships that could be construed as a potential conflict of interest.

Copyright (c) 2015 Beaume, Köhler, Fontana, Tognon, Renzoni and van Delden. This is an open-access article distributed under the terms of the Creative Commons Attribution License (CC BY). The use, distribution or reproduction in other forums is permitted, provided the original author(s) or licensor are credited and that the original publication in this journal is cited, in accordance with accepted academic practice. No use, distribution or reproduction is permitted which does not comply with these terms. 